plays a significant role in reducing the DNA rate in the Paediatric outpatient setting. Telephone reminders and text messaging are extremely cost effective interventions, and hence routine reminders with confirmation of appointment should become standard NHS practice.

\section{G288 A REGIONAL REVIEW OF HUMIDIFIED HIGH FLOW NASAL CANNULA OXYGEN USE IN CHILDREN}

${ }^{1}$ LE Milne, ${ }^{2} \mathrm{~J}$ Pappachan, ${ }^{3} \mathrm{M}$ Linney, ${ }^{4} \mathrm{~K}$ Pryde, ${ }^{5} \mathrm{~K}$ Pike. ${ }^{1}$ Paediatric Department, Portsmouth Hospitals Trust, Portsmouth, UK; ${ }^{2}$ Paediatric Intensive Care Unit, University Hospital Southampton NHS Foundation Trust, Southampton, UK; ${ }^{3}$ Paediatric Department, Western Susssex Hospitals NHS Foundation Trust, Chichester, UK; ${ }^{4}$ Paediatric Department, University Hospital Southampton NHS Foundation Trust, Southampton, UK; ${ }^{5}$ Paediatric Respiratory Medicine, University of Southampton, Southampton, UK

\subsection{6/archdischild-2015-308599.265}

The aims of this review were four fold

1. To document the non-intensive care paediatric experience at a regional level of oxygen delivered via high flow humidified nasal cannulae (HHFNC).

2. To understand patient outcomes and safety data with respect to HHFNC oxygen.

3. To determine whether clinical data might help identify those children most likely to deteriorate on HHFNC oxygen.

4. To create a region wide guideline based on the findings.

Data was collected between October 2013 and April 2014. A pro forma was completed by local paediatric teams at all 10 hospitals within the regional critical care network on all episodes of the use of HHFNC oxygen. To inform guideline needs of the region, questionnaires about the use of HHFNC oxygen were completed by nursing and medical staff.

210 episodes of HHFNC oxygen use were captured. Experience with HHFNC oxygen varied widely within the region. It was used most frequently in children under a year of age diagnosed with bronchiolitis. Children with bronchiolitis who deteriorated whilst receiving HHFNC oxygen had a lower $\mathrm{pH}$ and higher work of breathing score two hours after commencing this form of respiratory support (Table 1 ). The proportion of infants with bronchiolitis receiving HHFNC oxygen who required intubation and ventilation was lower than found in a previous regional review in 2008 when continuous positive airways pressure (CPAP) was the standard means of providing respiratory support. Bronchiolitic infants receiving HHFNC oxygen

Abstract G288 Table 1 Trends in children with bronchiolitis on HHFNC oxygen who deteriorated (escalated to CPAP, or intubation and ventilation), compared to those who did not deteriorate

\begin{tabular}{ll|ll}
\hline & Deteriorated & $\begin{array}{l}\text { Did not } \\
\text { deteriorate }\end{array}$ & P value \\
\hline $\begin{array}{l}\text { pH pre HHFNC oxygen } \\
\text { Mean, (Standard Deviation) }\end{array}$ & $\begin{array}{l}7.27,(0.076) \\
\mathrm{n}=17\end{array}$ & $\begin{array}{l}7.31,(0.072) \\
\mathrm{n}=69\end{array}$ & 0.018 \\
$\begin{array}{l}\text { pH at 2 hours of HHFW C oxygen } \\
\text { Mean, (Standard Deviation) }\end{array}$ & $\begin{array}{l}7.31(0.104) \\
\mathrm{n}=16\end{array}$ & $\begin{array}{l}7.37(0.049) \\
\mathrm{n}=47\end{array}$ & 0.004 \\
\hline $\begin{array}{l}\text { Work of breathing score at 2 } \\
\text { hours of HHFWC oxygen } \\
\text { Mean, (Inter-quartile range) }\end{array}$ & $\begin{array}{l}8,(7-9) \\
\mathrm{n}=21\end{array}$ & $\begin{array}{l}7,(5-7) \\
\mathrm{n}=86\end{array}$ & 0.005 \\
\hline
\end{tabular}

remained less likely to require intubation, even when adjusted for initial $\mathrm{pH}<7.25$ as an indicator of severity (16\% v 46\%) (Table 1).

The use of HHFNC oxygen has become widespread in our general paediatric population. Our review demonstrates that HHFNC oxygen is safe in children for a variety of conditions, ages and weights. The use of blood gases and assessment of work of breathing pre and two hours after starting HHFNC oxygen could help identify those at risk of deteriorating. There is a suggestion that HHFNC oxygen may reduce the intubation and ventilation rate of children with bronchiolitis. A regional guideline has been designed based on these findings.

\section{G289 INCREASING PARENT RESILIENCE IN CHRONIC PAEDIATRIC CONDITIONS: THE CASE OF CHRONIC PAIN}

J Gauntlett-Gilbert, J Clinch, H Connell, V Rogers. Bath Centre for Pain Services, Royal National Hospital for Rheumatic Diseases NHS Foundation Trust, Bath, UK

\subsection{6/archdischild-2015-308599.266}

Aims Parenting a child with a chronic health condition can be difficult. Parent wellbeing is important in its own right, and also for the sake of the child. Parents who become, albeit understandably, anxious, over-protective or detached from their ill children may not provide them with ideal support. Where a child's illness improves, parental stress is likely to decrease. However, there are a range of conditions where a child's underlying health remains problematic. We aimed to establish whether parent resilience could be improved in the face of ongoing symptoms, in this case, in a population of adolescents undergoing treatment for chronic pain.

Methods 92 parents accompanied their child (adolescent, ages 11-18) for a course of residential treatment for non-malignant chronic pain. The adolescents had disabling idiopathic pain requiring treatment at a tertiary national specialist service. Parents accompanied their children through most of the three week programme, participating in exercise and psychology sessions, as well as having three hours of dedicated parent intervention. We examined (1) parental catastrophising about pain, (2) parenting behaviour and (3) parent stress up to a three month follow up.

Results Adolescents going through the programme showed no change in their underlying pain intensity, which remained high $(7.7 / 10)$. They did make functional improvements. Despite ongoing adolescent pain, parents at the three month follow up period ( $\mathrm{n}-72,76 \%$ data completion) showed significantly decreased catastrophizing about their child's pain, less protective parenting behaviour, and reduced parenting stress. Parents showed a decrease in defensive responding around their child, and did not show any increase in their tendency to 'minimise' their child's ongoing pain.

Conclusions Parents can increase their resilience and show increasingly adaptive parenting, even in cases where their child's underlying condition does not improve. Here, parents were exposed to a programme of intensive psychological and physical rehabilitation with some dedicated sessions targeted at parent resilience. Their children's pain did not change, but their approach to it did. However, the intervention studied was targeted both at child and parent; research is needed to establish whether parent-only interventions can improve resilience. 